\title{
TSH-secreting pituitary adenomas treated by gamma knife radiosurgery: our case experience and a review of the literature
}

\author{
Zadalla Mouslech, ${ }^{1}$ Maria Somali, ${ }^{2}$ Anastasia Konstantina Sakali, ${ }^{2}$ \\ Christos Savopoulos, ${ }^{1}$ George Mastorakos, ${ }^{2}$ Apostolos I. Hatzitolios ${ }^{1}$ \\ ${ }^{1} 1^{\text {st }}$ Medical Propedeutic Dept of Internal Medicine, AHEPA University Hospital, Aristotle University of Thessaloniki, \\ Thessaloniki, Greece, ${ }^{2}$ Department of Endocrinology, Metabolism and Diabetes, Aretaieio Hospital, School of Medicine, \\ University of Athens, Athens, Greece
}

\begin{abstract}
A 43-year-old woman, previously misdiagnosed as having primary hyperthyroidism and treated with antithyroid drugs, presented to us with overt hyperthyroidism, high levels of thyroid hormones and elevated thyroid-stimulating hormone (TSH). Magnetic resonance imaging (MRI) revealed a pituitary microadenoma extending suprasellarly. The patient responded favorably to initial treatment with somatostatin analogs for 2 years but due to the escape phenomenon, TSH levels escalated and hyperthyroidism relapsed. Transsphenoidal adenomectomy was applied but recurrence was again observed due to incomplete tumor removal. Gamma knife radiosurgery was finally employed 5.5 years ago, resulting in complete disease remission without evidence of long-term complications to date. Thyrotropin-secreting adenomas (TSHomas) are rare with an estimated prevalence of about one case per million. We retrieved from the literature 14 cases of TSHomas treated by gamma knife radiosurgery and compared the outcomes. Our results demonstrate the efficacy and safety of gamma knife radiosurgery for achieving remission in most of the cases, suggesting validation of this technique as an effective treatment option for the management of recurrent TSHomas.
\end{abstract}

Key words: Thyrotropin-secreting pituitary adenoma, Hyperthyroidism, Long-acting somatostatin analogs, Transsphenoidal adenomectomy, Gamma knife radiosurgery, Long-term remission

\section{INTRODUCTION}

Among pituitary adenomas, thyrotropin-secreting

Address for correspondence:

Zadalla Mouslech, MD, PhD, Endocrinologist,

112 Tsimiski street, Postcode 546 22, Thessaloniki, Greece;

Tel.: +30 2310 266471, Mobile: +30 6977341046,

Fax: +30 2310 266471, E-mail: mousalz@endo.gr

Received: 12-08-2015, Accepted: 19-11-2015 adenomas (TSHomas) have the lowest prevalence, accounting for $0.5-2.8 \%$ of all pituitary adenomas. ${ }^{1-4}$ The first case was reported in 1960 by Jailer and Holub $^{5}$ and since then just over 450 cases have been published in the literature. About $70 \%$ of TSHomas are pure adenomas, while the rest are mixed, co-secreting mainly growth hormone $(\mathrm{GH})$ and prolactin (PRL). ${ }^{6}$ The treatment of choice for TSHomas is surgical 
removal of the tumor by the transsphenoidal or subfrontal approach. However, radical removal is usually impossible due to invasion of surrounding structures and to the fibrous nature of these tumors, resulting in high recurrence or failure rates of $47-78 \% 0^{7-10}$ If surgery is contraindicated or if it fails to cure, the European Thyroid Association guidelines strongly recommend treatment with somatostatin analogs (SSA), such as octreotide and lanreotide, which have proved to be highly effective in a series of studies. ${ }^{9-19}$ However, there are cases where manifestation of adverse effects, resistance to or escape from the inhibitory effect of SSAs lead to failure of treatment. ${ }^{15,18,19}$ In these cases stereotactic irradiation can be employed. ${ }^{11}$

Stereotactic irradiation can be delivered either in multiple sessions (fractionated stereotactic radiotherapy or FSRT) or in a single session (stereotactic radiosurgery or SRS). Today, gamma knife (GK) is the most widespread radiosurgical method. Its accuracy is comparable to a surgical blade, though it should not be employed for targets bigger than $4 \mathrm{~cm}$ since they need larger irradiation beams, producing more damage to surrounding structures. Although GK has to date been used successfully in the treatment of pituitary tumors for almost 50 years (a review by Koga et $\mathrm{al}^{20}$ reports the sizeable number of 38,553 pituitary adenomas treated by gamma knife up to 2008), to our best knowledge only 14 cases of TSHomas treated by GK have been reported in the literature. ${ }^{7-9,21-25}$ Due to the small number of reported cases and their scant follow-up, few data are available on the long-term efficacy and safety of this technique in the treatment of TSHomas. Here, we describe a case of a recurrent TSHoma where gamma knife radiosurgery induced long-term control of the disease and we review the literature on the outcome of TSHoma cases treated by the same means.

\section{CASE REPORT}

A 43-year-old woman presented in 2002 to our department complaining of palpitations. Eight years earlier she had been diagnosed with primary hyperthyroidism and treated with antithyroid drugs ever since. She reported recurrence of hyperthyroidism following every attempt to discontinue medical treatment.

On physical examination she had tremor, extra- systolic arrhythmia and a palpable thyroid gland. Hormonal assessment revealed high free circulating thyroid hormones $\left(\mathrm{FT}_{4}=32 \mathrm{pmol} / \mathrm{L}\right.$, n.v. $11-25$ and $\mathrm{FT}_{3}=12 \mathrm{pmol} / \mathrm{L}$, n.v. 3.3-8.2) and high TSH concentrations $(\mathrm{TSH}=12.5 \mathrm{mIU} / \mathrm{L}$, n.v. $0.3-4)$. The rest of the anterior pituitary hormones were within normal range. The response of TSH to TRH stimulation test was blunted (TSH $0 \mathrm{~min}=11.5$, TSH $30 \mathrm{~min}=15.3$, and $\mathrm{TSH} 60 \mathrm{~min}=13.5 \mathrm{mIU} / \mathrm{L}$ ), suggesting the presence of a TSHoma. Thyroid ultrasonography demonstrated diffuse enlargement of the thyroid gland and magnetic resonance imaging (MRI) confirmed the presence of a pituitary microadenoma of $9 \mathrm{~mm}$ in diameter which extended suprasellarly (Figure 1). A pituitary scintigraphy with radiolabeled octreotide revealed high uptake of the octreotide by the pituitary gland, thus confirming the presence of somatostatin receptors.

The patient refused surgical removal of the tumor and was initially treated with a combination of lanreotide and antithyroid drugs. Lanreotide was started at a dose of $60 \mathrm{mg}$ once monthly which was gradually escalated to $120 \mathrm{mg}$. Consequently, a euthyroid state was restored and the tumor shrank by 2 $\mathrm{mm}$. These favorable results lasted up to 2 years, at which point, in 2004, the hyperthyroidism relapsed indicating that TSH secretion had escaped from the inhibitory effect of the somatostatin analog. Tumor size steadily increased and by 2006 it again measured $9 \mathrm{~mm}$ in diameter in MRI visualization, while TSH, $\mathrm{FT}_{4}$ and $\mathrm{FT}_{3}$ levels averaged $30.39 \mathrm{mIU} / \mathrm{L}, 34 \mathrm{pmol} / \mathrm{L}$ and $13 \mathrm{pmol} / \mathrm{L}$, respectively (Figure 2 ). After a sudden episode of paroxysmal atrial fibrillation, which resulted in hospitalization, the patient gave consent and underwent endonasal transsphenoidal adenomectomy on 29/6/2006. Postoperative MRI revealed a residual tumor mass of $3 \mathrm{~mm}$ in diameter, while postoperative TSH decreased to $5 \mathrm{mIU} / \mathrm{L}$. Histological examination by immunohistochemistry proved positive for TSH and negative for GH, PRL, FSH, LH and $\mathrm{ACTH}$, confirming the diagnosis of a pure TSHoma. Further molecular and pathological analysis, such as the determination of the Ki-67 signaling index, was not conducted.

One year later TSH concentrations had increased to 9.0mIU/L with FT3 and FT4 values within the upper normal range. Alternative treatment with radiosurgery was proposed to the patient, which was initially 
refused. While waiting for her decision whether or not to undergo radiosurgery the patient became hyperthyroid. We chose to administer antithyroid drugs based on our previous experience with lanreotide, which proved to be inefficient in this patient in the long run. In 2009, TSH reached its highest ever level of $78 \mathrm{mIU} / \mathrm{L}$, while in the MRI visualization the size of the residual adenomatous tissue had slightly increased to $0.4 \times 0.2 \mathrm{~cm}$. In May 2010, the patient finally

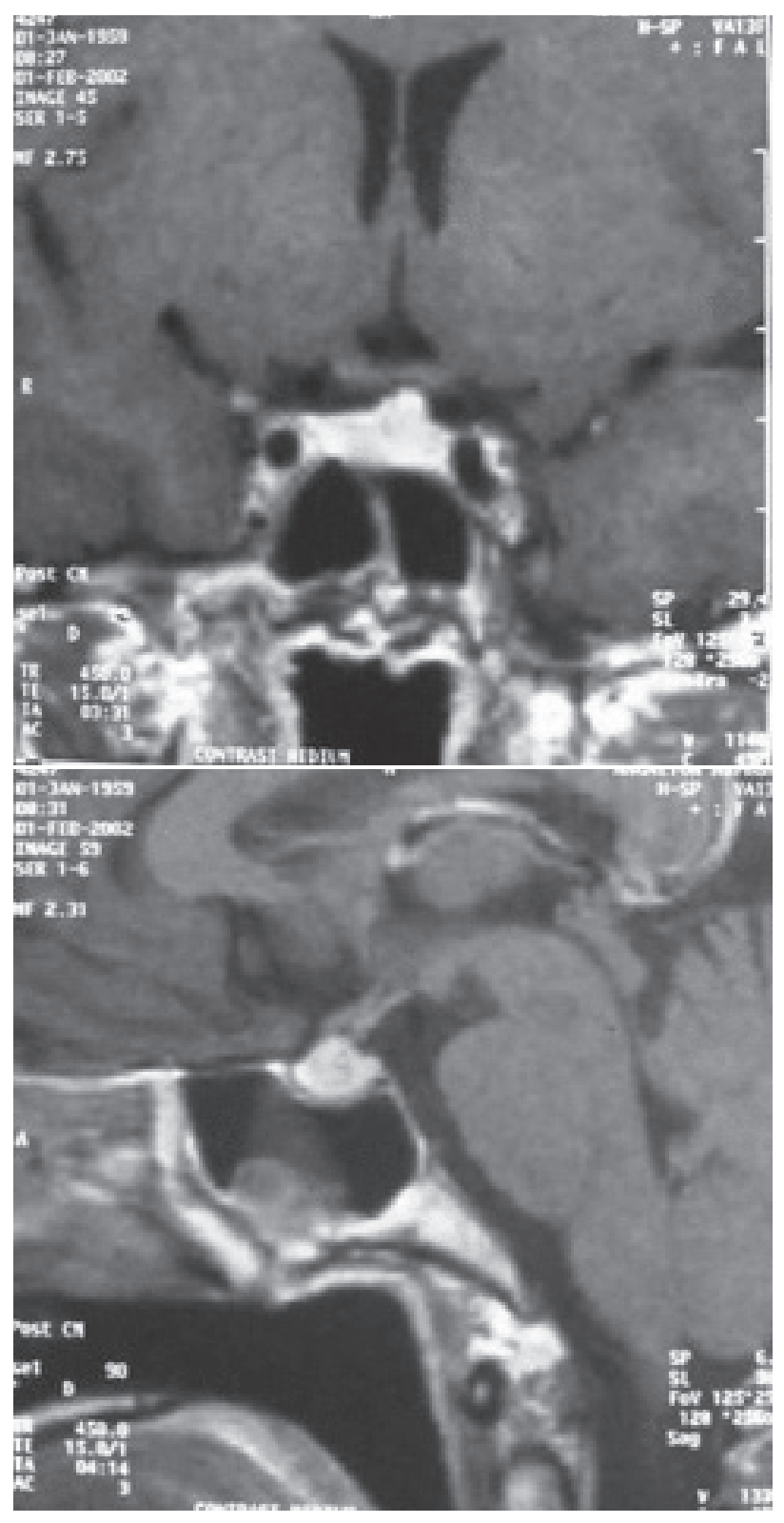

Figure 1. Coronal (a) and sagittal (b) MRI images of the pituitary gland, revealing a pituitary adenoma, $9 \mathrm{~mm}$ in diameter at diagnosis (February 2002). underwent stereotactic radiosurgery with Leksell Gamma Knife ${ }^{\circledR}$ Perfexion, which led to normalization of thyroid hormone secretion and disappearance of the pituitary lesion, as shown in post-radiation MRI. The patient did not experience any side effects from this treatment.

To date, 5.5 years after radiosurgery (October 2015), the patient has remained euthyroid without any treatment $\left(\mathrm{TSH}=3.76 \mathrm{mIU} / \mathrm{L}\right.$, n.v. $0.3-4.2, \mathrm{FT}_{4}=0.94$ $\mathrm{ng} / \mathrm{dl}$, n.v. $0.8-2$ and $\mathrm{FT}_{3}=3.30 \mathrm{pg} / \mathrm{ml}$, n.v. 2-4.4) and without experiencing any short-term or long-term complications. Recent MRI visualization, performed in 2013, showed no evidence of the pituitary adenoma (Figure 3).

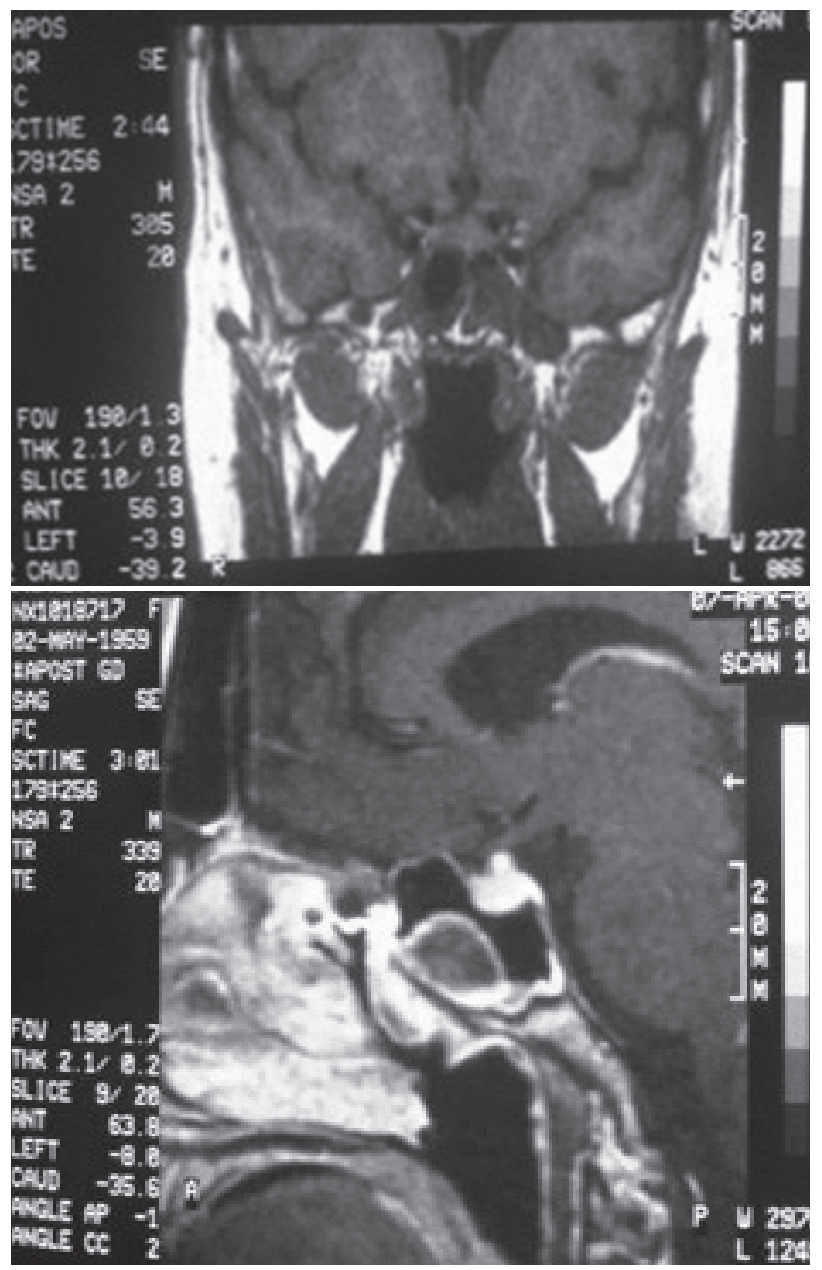

Figure 2. Coronal (a) and sagittal (b) MRI images of the pituitary gland, prior to transsphenoidal adenomectomy (April 2006) visualizing a pituitary adenoma, $9 \mathrm{~mm}$ at its maximum diameter. The images were taken after failure of treatment with lanreotide for 2 years. 


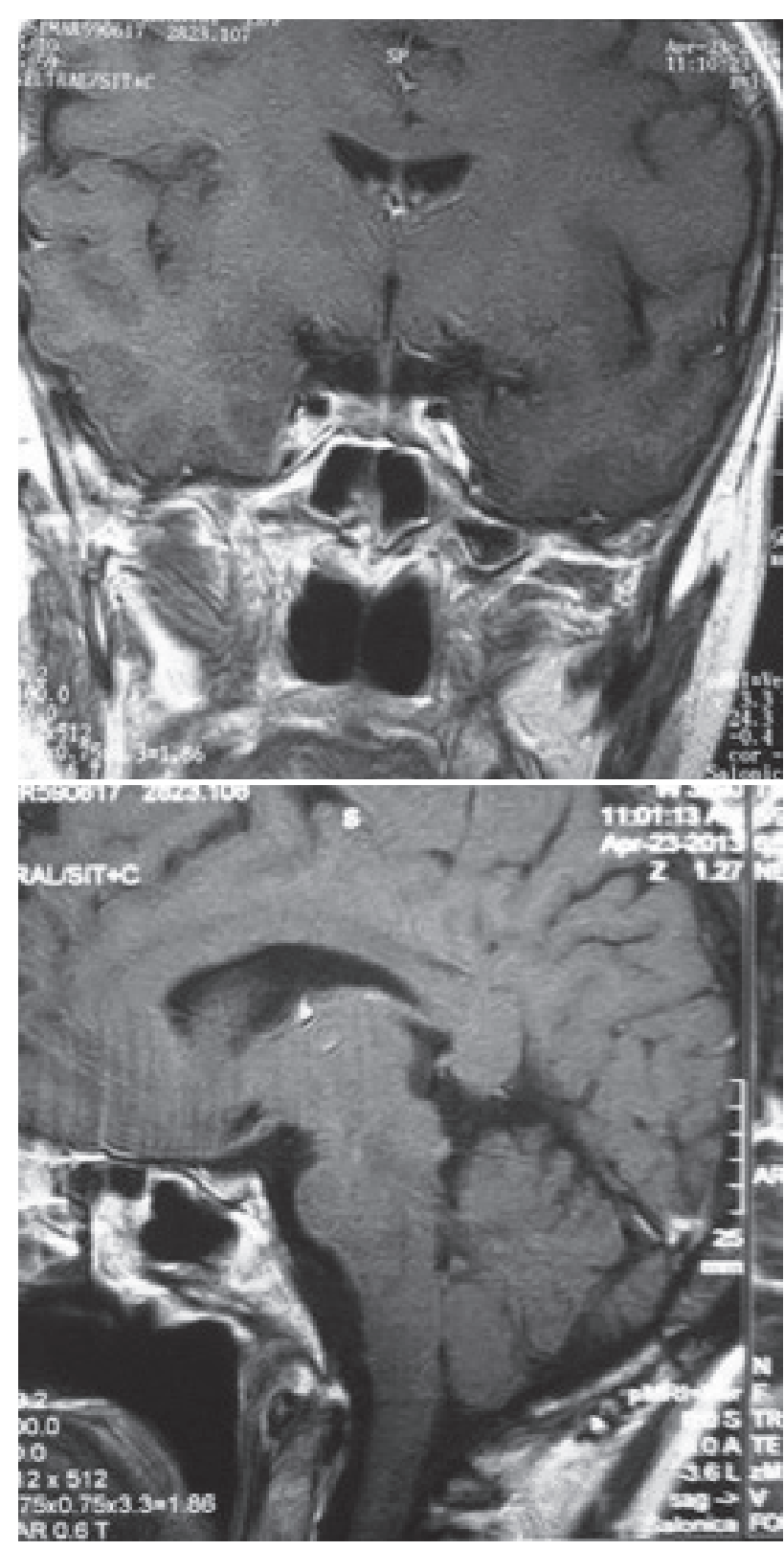

Figure 3. Recent coronal (a) and sagittal (b) MRI images of the pituitary gland, at 3 years follow-up after successful gamma knife radiosurgery, showing absence of residual tumor (April 2013).

\section{DISCUSSION AND REVIEW OF THE LITERATURE}

We present a case of TSHoma successfully treated with gamma knife surgery after failure of conventional surgery and escape from somatostatin analog adjuvant therapy. The gold standard of TSHomas treatment is surgical removal of the tumor. Recent data from a retrospective study published by Gatto et al report a post-surgical complications rate of $60 \%$ as regards TSHomas, while the same figure is only $12 \%$ in the case of GHomas matched for age, sex and tumor size. ${ }^{26}$ In our presented case, surgical adenomectomy was performed without any complication but resulted in incomplete removal leaving a residual mass of $3 \mathrm{~mm}$ in diameter, and recurrence occurred a little over a year postoperatively.

When surgery fails to cure, as in this case, or if it is contraindicated, medical treatment with somatostatin analogs can be implemented. Two cases of TSHomas effectively treated with SSA monotherapy have recently been published. ${ }^{27,28}$ Most TSHomas express somatostatin receptors and are considered highly sensitive to SSAs. However, common side effects of these drugs, such as gastrointestinal disturbances, cholelithiasis and glucose intolerance as well as resistance to treatment and the TSH escape phenomenon, often contribute to treatment failure. Escape from efficacious treatment was the reason for discontinuing it in this case. Alternative treatment employed in cases of recurrence has been stereotactic irradiation. Stereotactic irradiation of pituitary adenomas is mainly performed with the use of the gamma knife radiosurgery method. A recent review of published studies conducted from 2000 to 2014 on the long-term efficacy and safety of GK treatment for either non-functioning or GH-, ACTH- and PRLsecreting pituitary adenomas treated mainly with GK radiosurgery by Minniti et al indicates excellent longterm tumor control (85-100\%), long-term biochemical remission in about $50 \%$ of the cases, no significant visual complications and a relatively low (15-35\%) incidence of late radiation-induced hypopituitarism. ${ }^{29}$ We retrieved 14 published cases of TSHomas treated by gamma knife radiosurgery (Table 1 ). However, due to the rarity of the tumors, data on the longterm efficacy and safety of the method in the case of TSHomas are anecdotal.

In many of these 14 cases of TSHomas treated by gamma knife, information regarding tumor size, grade of extrasellar invasiveness and irradiation is missing. Wherever it is available, it is striking that by the time of diagnosis most of the tumors presented extrasellar extension and in terms of size they were 
Table 1. Reported cases of TSHomas treated by gamma knife radiosurgery

\begin{tabular}{|c|c|c|c|c|c|c|c|}
\hline Reference & $\mathrm{N}$, sex & $\begin{array}{c}\text { Age } \\
\text { (years) }\end{array}$ & Size & Treatment & Follow-up & $\begin{array}{l}\text { Outcome } \\
\text { (Thyroid } \\
\text { function) }\end{array}$ & $\begin{array}{l}\text { Outcome } \\
\text { (MRI) }\end{array}$ \\
\hline $\begin{array}{l}\text { Brucker-Davis, } \\
1999^{7}\end{array}$ & $1, \mathrm{~F}$ & 63 & macro & TSS, GK & 1 year & $\begin{array}{c}\text { Euthyroid, } \\
\alpha \text {-subunit } \\
\text { normalization }\end{array}$ & $\begin{array}{c}\text { Residual } \\
\text { macrotumor }\end{array}$ \\
\hline Losa, $1999^{8}$ & $\begin{array}{c}3, \mathrm{NA} \\
1, \mathrm{~F}\end{array}$ & NA & $\begin{array}{l}3 \mathrm{NA}, \\
1 \text { macro }\end{array}$ & TSS, GK & $\begin{array}{l}\text { Up to } \\
2 \text { years }\end{array}$ & $\begin{array}{l}3 \text { Euthyroid, } \\
1 \text { Hypothyroid }\end{array}$ & $\begin{array}{l}2 \text { Reduction } \\
\text { in size, } \\
2 \text { Stable }\end{array}$ \\
\hline Ohki, $1999^{21}$ & $1, \mathrm{~F}$ & 64 & macro-invasive & TSS,GK & 16 months & Euthyroid & NA \\
\hline Kon, $2001^{22}$ & $1, \mathrm{M}$ & 52 & macro-invasive & $\begin{array}{l}\text { TSS, SSA, } \\
\text { cabergoline, } \\
\text { repeated TSS, } \\
\text { GK }\end{array}$ & $\begin{array}{l}7 \text { months } \\
\text { Under SSA } \\
\text { treatment }\end{array}$ & Euthyroid & NA \\
\hline Socin, $2003^{9}$ & $1, \mathrm{NA}$ & NA & NA & TSS, GK irradiation & NA & NA & NA \\
\hline Clarke, $2008^{23}$ & $1, \mathrm{NA}$ & NA & NA & TSS, GK & NA & NA & NA \\
\hline $\begin{array}{l}\text { Kasliwal, } \\
2012^{24}\end{array}$ & $1, \mathrm{M}$ & 24 & NA & $\begin{array}{c}\text { Preoperative } \\
\text { stabilization with } \\
\text { SSA, TSS, GK }\end{array}$ & 1 year & Euthyroid & $\begin{array}{l}\text { Reduction } \\
\text { in size }\end{array}$ \\
\hline Zhao, $2012^{25}$ & $4, \mathrm{M}$ & $57,17,50,48$ & $\begin{array}{c}1 \text { micro, } \\
2 \text { giant-invasive, } \\
1 \text { macro-invasive }\end{array}$ & $\begin{array}{c}\text { 1GK alone, } \\
\text { 3SSA, TSS, GK }\end{array}$ & $\begin{array}{c}3 \text { years, } \\
2 \text { years, } \\
1 \text { year, } \\
4 \text { months }\end{array}$ & Euthyroid & $\begin{array}{l}\text { Residual } \\
\text { tumor }\end{array}$ \\
\hline $\begin{array}{l}\text { Present case, } \\
2015\end{array}$ & $1, \mathrm{~F}$ & 43 & micro-invasive & SSA, TSS, GK & 5.5 years & Euthyroid & $\begin{array}{l}\text { No evidence } \\
\text { of adenoma }\end{array}$ \\
\hline
\end{tabular}

M: male; F: female; TSS: transsphenoidal surgery; GK: gamma-knife; MRI: magnetic resonance imaging; NA: not available; SSA: somatostatin analogs.

macroadenomas ( $\geq 1 \mathrm{~cm}$ at their maximum diameter). In two cases reported by Zhao et al, the TSHoma was giant-sized, measuring more than $4 \mathrm{~cm}$ at its maximum diameter, whereas in one case reported by the same researchers the TSHoma was a microadenoma. The latter is the only case reported in the literature as having been treated by GK radiosurgery alone. In the rest of the cases, as well as in our case, gamma knife radiosurgery was performed as a second-line treatment on the residual tumor after transsphenoidal adenometomy. In some of the reported cases, medical treatment with SSA was implemented for a short period preoperatively to induce biochemical control and tumor shrinkage and thereby ensure better postoperative results. In the presented case, the use of SSA was extended for a much longer period of time because of the patient's refusal to undergo transsphenoidal surgery as a primary treatment. In one case reported by Kon et al, SSA treatment was applied for a year after the implementation of GK radiosurgery in order to control the disease until the radiosurgery effect became fully apparent. This might be a useful practice, as a recently published retrospective study on a series of pituitary adenomas by Mak et al indicated that statistically significant tumor size reduction occurs not earlier than 1 year after GK radiosurgery administration. Further reduction, to a lesser extent, continues during the following years as well. ${ }^{30} \mathrm{~A}$ recent review and meta-analysis by Chen, Li et al carried out on a series of non-functioning pituitary adenomas indicated that tumor volume has a statistically significant predictive value of GK effectiveness and safety. Tumor volumes under $4 \mathrm{ml}$ were associated with better tumor control and fewer 
radiation-induced complications. ${ }^{31}$ This knowledge could also be applicable to TSH tumors. It should be mentioned that in spite of the fact that most TSHomas studied were sizeable by the time of diagnosis, the majority of them received irradiation after surgical removal, when the residual mass was much smaller, probably resulting in higher post-radiation control rates. Another important predictive marker of GK safety is the radiation dose. In order to avoid hypopituitarism, Marek et al highlighted in their study the need to keep the mean radiation dose to pituitary tissue surrounding the adenoma under 15 Gy and the maximum dose to the distal infundibulum under 17 Gy. ${ }^{32}$ Similarly, in their review Leavitt et al indicated that the maximum radiation dose to the anterior visual pathway should be kept under 12 Gy in order to avoid radiation-induced optic neuropathy. ${ }^{33}$ In the cases discussed here there is no information available on the delivered irradiation dose.

The follow-up in most of the reported cases was minimal, lasting from 4 months to 3 years, and only limited information was provided on the long-term efficacy and safety of the procedure. However, it is striking that in all the above cases where outcome information is available, biochemical remission and tumor control have been achieved without any reported complications. In the presented case follow-up has attained 5.5 years, the longest reported after the use of gamma knife treatment for a TSHoma, without the presence of residual tumor in the post-radiation MRIs performed.

Although there is limited available scientific evidence, on the basis of the favorable results of the previously reported cases of TSHomas treated with GK radiosurgery as well as of the long-term satisfactory outcome of the present case, we suggest that GK radiosurgery should in the future play a more prominent important role in the treatment of recurrent TSHomas. However, more studies based on larger series of patients and longer follow-up need to be conducted to corroborate our present suggestion.

\section{FUNDING}

This research did not receive any specific grant from any funding agency in the public, commercial or not-for-profit sector.

\section{DECLARATION OF INTEREST}

The authors declare that they have no conflict of interest.

\section{INFORMED CONSENT}

Informed consent was obtained from all individual participants included in the study.

\section{REFERENCES}

1. Mindermann T, Wilson CB, 1993 Thyrotropin-producing pituitary adenomas. J Neurosurg 79: 521-527.

2. Önnestam L, Berinder K, Burman P, et al, 2013 National Incidence and Prevalence of TSH-Secreting Pituitary Adenomas in Sweden. J Clin Endocrinol Metab 98: 626-635.

3. Raappana A, Koivukangas J, Ebeling T, Pirilä T, 2010 Incidence of pituitary adenomas in Northern Finland in 1992-2007. J Clin Endocrinol Metab 95: 4268-4275.

4. Gruppetta M, Mercieca C, Vassallo J, 2013 Prevalence and incidence of pituitary adenomas: a population based study in Malta. Pituitary 16: 545-553.

5. Jailer JW, Holub DA, 1960 Remission of Graves' disease following radiotherapy of a pituitary neoplasm. Am J Med 28: 497-500.

6. Beck-Peccoz P, Persani L, Lania A 2015 Thyrotropin-Secreting Pituitary Adenomas. In: De Groot LJ, Beck-Peccoz P, Chrousos G et al, (eds) Endotext [Internet]. South Dartmouth (MA): MDText.com, Inc.; Available at: http://www.ncbi.nlm.nih.gov/ books/NBK278978/

7. Brucker-Davis F, Oldfield EH, Skarulis MC, Doppman JL, Weintraub BD, 1999 Thyrotropin-secreting pituitary tumors: diagnostic criteria, thyroid hormone sensitivity, and treatment outcome in 25 patients followed at the National Institutes Of Health. J Clin Endocrinol Metab 84: 476-486.

8. Losa M, Mortini P, Franzin A, Barzaghi R, Mandelli C, Giovanelli M, 1999 Surgical management of thyrotropinsecreting pituitary adenomas. Pituitary 2: 127-131.

9. Socin H, Chanson P, Delemer B, et al, 2003 The changing spectrum of TSH-secreting pituitary adenomas: diagnosis and management in 43 patients. Eur J Endocrinol 148: 433-442.

10. Van Varsseveld NC, Bisschop PHLT, Biermasz NR, Pereira AM, Fliers E, Drent ML, 2014 A long-term follow-up study of eighteen patients with thyrotrophinsecreting pituitary adenomas. Clin Endocrinol (Oxf) 80: 395-402.

11. Beck-Peccoz P, Lania A, Beckers A, Chatterjee K, Wemeau J-L, 2013 European thyroid association guidelines for the diagnosis and treatment of thyrotropin-secreting pituitary tumors. Eur Thyroid J 2: 76-82. 
12. Ness-Abramof R, Ishay A, Harel G, et al, 2007 TSHsecreting pituitary adenomas: follow-up of 11 cases and review of the literature. Pituitary 10: 307-310.

13. Kessler M, David R, Pawelczak M, Hanono A, Shah B, 2010 Thyrotropin-Secreting Pituitary Adenoma in an Adolescent Boy: Challenges in Management. Pediatrics 126: e474-478.

14. Beck-Peccoz P, Persani L, 2002 Medical management of thyrotropin-secreting pituitary adenomas. Pituitary 5: 83-88.

15. Chanson P, Weintraub BD, Harris AG, 1993 Octreotide therapy for thyroid-stimulating hormone-secreting pituitary adenomas: A Follow-up of 52 patients. Ann Intern Med 119: 236-240.

16. Prieto-Tenreiro A, Díaz-Guardiola P, 2010 Long term treatment of a thyrotropin-secreting microadenoma with somatostatin analogues. Arq Bras Endocrinol Metab 54: 502-506.

17. Kuhn JM, Arlot S, Lefebvre H, et al, 2000 Evaluation of the treatment of thyrotropin-secreting pituitary adenomas with a slow release formulation of the somatostatin analog lanreotide. J Clin Endocrinol Metab 85: 1487-1491.

18. Gatto F, Barbieri F, Gatti M, et al, 2012 Balance between somatostatin and D2 receptor expression drives TSH-secreting adenoma response to somatostatin analogues and dopastatins. Clin Endocrinol (Oxf) 76: 407-414.

19. Elston MS, Conaglen JV, 2010 Clinical and biochemical characteristics of patients with thyroid-stimulating hormone-secreting pituitary adenomas from one New Zealand centre. Intern Med J 40: 214-219.

20. Koga T, Shin M, Saito N, 2010 Role of $\gamma$ knife radiosurgery in neurosurgery: past and future perspectives. Neurol Med Chir (Tokyo) 50: 737-748.

21. Ohki M, Sato K, Tuchiya D, et al, 1999 A case of TSH-secreting pituitary adenoma associated with an unruptured aneurysm: successful treatment by twostage operation and gamma-knife. No To Shinkei 51: 895-899.

22. Kon YC, Loh KC, Tambyah JA, Lim LH, Marshall JC, 2001 Thyrotrophin (TSH)-secreting pituitary macroadenoma with cavernous sinus invasion. Singapore Med J 42: 433-437.
23. Clarke MJ, Erickson D, Castro MR, Atkinson JLD, 2008 Thyroid-stimulating hormone pituitary adenomas. J Neurosurg 109: 17-22.

24. Kasliwal M, Gupta A, Sharma M, 2012 Single low dose adjuvant Gamma knife radiosurgery for thyrotropin secreting pituitary adenoma. Acta Neurochir 154: 665666.

25. Zhao W, Ye H, Li Y, et al, 2012 Thyrotropin-secreting pituitary adenomas: diagnosis and management of patients from one Chinese center. Wien Klin Wochenschr 124: 678-684.

26. Gatto F, Grasso LF, Nazzari E, et al, 2015 Clinical outcome and evidence of high rate post-surgical anterior hypopituitarism in a cohort of TSH-secreting adenoma patients: Might somatostatin analogs have a role as first-line therapy? Pituitary 18: 583-591.

27. Fliers E, van Furth WR, Bisschop PH, 2012 Cure of a thyrotrophin (TSH)-secreting pituitary adenoma by medical therapy. Clin Endocrinol (Oxf) 77: 788-790.

28. Rabbiosi S, Peroni E, Tronconi GM, Chiumello G, Losa M, Weber G, 2012 Asymptomatic ThyrotropinSecreting Pituitary Macroadenoma in a 13-Year-Old Girl: Successful First-Line Treatment with Somatostatin Analogs. Thyroid 22: 1076-1079.

29. Minniti G, Clarke E, Scaringi C, Enrici RM, 2014 Stereotactic radiotherapy and radiosurgery for nonfunctioning and secreting pituitary adenomas. Rep Pract Oncol Radiother. Available at: http://www.sciencedirect.com/science/article/pii/S1507136714001497.

30. Mak HK-F, Lai S-W, Qian W, et al, 2014 Effective time window in reducing pituitary adenoma size by gamma knife radiosurgery. Pituitary 18: 509-517.

31. Chen Y, Li ZF, Zhang FX, et al, 2013 Gamma knife surgery for patients with volumetric classification of nonfunctioning pituitary adenomas: a systematic review and meta-analysis. Eur J Endocrinol 169: 487-495.

32. Marek J, Ježková J, Hána V, et al, 2011 Is it possible to avoid hypopituitarism after irradiation of pituitary adenomas by the Leksell gamma knife? Eur J Endocrinol 164: 169-178.

33. Leavitt JA, Stafford SL, Link MJ, Pollock BE, 2013 Long-term evaluation of radiation-induced optic neuropathy after single-fraction stereotactic radiosurgery. Int J Radiat Oncol Biol Phys 87: 524-527. 